\title{
Global Crisis: Problems and Prospects for Indian Banking Industry
}

\author{
R. K. Uppal \\ D. A. V. College, Malout (Punjab), India \\ rkuppal_mlt@yahoo.com
}

\begin{abstract}
The present paper analyses the efficiency of all the bank groups in the post- banking sector reforms era. Time period of the study is related to second post-banking sector reforms (1999-2000 to 2005-06). This period has been chosen taking into consideration the following factors; On the basis of some parameters of efficiency i.e. profitability per employee, per branch, business per employee, per branch and expenses per employee and per branch, the paper concludes that efficiency of all the bank groups has increased in the second post-banking reforms period but these banking sector reforms are more beneficial for new private sector banks and foreign banks. At the end, paper suggests some measures for the improvement of efficiency of Indian nationalized banks.
\end{abstract}

Key Words: Banking Sector Reforms, Efficiency Parameters, Future areas of Research, Implications of the study and conclusion

\section{Introduction}

The process of interest rate liberalization, which started in 1992, was fully liberalized (especially that of deposit rate) in 1998. New private sector banks started entering the banking business in a big way from 1998 Also, the second phase of liberalization in the banking sector started in 1997-98 following the recommendations of the second Narasimham Committee Report in 1998. The Indian financial system comprising commercial banks, the financial institutions and capital markets, has undergone a very rapid transformation. The committee on financial system, well known as the Narasimham Committee, set up in 1991, to recommend measures for bringing about necessary reforms in the financial sector. The first Narasimham Committee found the following distortions in Indian commercial banking:

- Deterioration in the quality of the loan portfolio because of fixation of targets for specific sector lending.

- Inadequate attention to quantitative aspects of lending.

- Improper loan appraisal of credit applications.

- $\quad$ No post-credit supervision and monitoring.

- Growth of overdue and consequent erosion of profitability.

The NC had proposed wide ranging reforms for:

- Improving the financial viability of the banks.

- Increasing their autonomy from government direction.

- Restructuring unviable banks.

- Allowing a greater entry to the private sector in banking.

- Liberalizing the capital markets.

- Setting up of proper supervisory system.

A number of reforms initiatives have been taken to remove or minimize the distortions impinging upon the efficient and profitable functioning of banks. These include the followings:

- $\quad$ Reduction in SLR \& CRR.

- Transparent guidelines or norms for entry and exit of private sector banks.

- Direct access to capital markets. 
- The regulated interest rate has been rationalized and simplified.

- Branch licensing policy has been liberalized.

- Merge strong banks, close weak unviable ones.

- Strengthen legal framework to accelerate credit recovery.

Overall, the main objective of the banking sector reforms was to improve the efficiency of the banks and prepare them to face the global competition. The post-bank scenario shows that gap between the efficiency in various bank groups has been widen. No doubt, Indian banks are improving their efficiency but the efficiency of foreign banks is much higher than other Indian bank groups.

\section{Review of Literature}

Harold (2006) has abstracted the balance score card (BSC) framework to develop a comprehensive performance measurement and management tool for IT in banking. In this paper, the author illustrates how a cascade of balanced scoreboards can be instrumental in the banking technology effectiveness of banks in India to ensure better performance measurement. Mariappan (2005-06) analyzed that IT revolution has brought stunning changing in the business environment perhaps no other sector has been influenced by advances in technology as much as banking and finance, as a result, the banking pose a totally new look today. Technology has been used a strategies to win market and customers. Patnaik (2004) his paper stress upon that shared ATMs is taking place and they are mutually beneficial. This mushrooming new dimension of shared ATMs has increased non-interest income of the banks. This is the most popular e-channel and widely used in all the bank groups. Singla (2008) examines that how financial management plays a crucial role industrialists growth of banking. It is concerned with examining the profitability position of the selected sixteen banks of banker index for a period of six years (2001-06). The study reveals that the profitability position was reasonable during the period of study when compared with the previous years. Strong capital position and balance sheet place. Banks in better position to deal with and absorb the economic constant over a period of time.

Srivastava (2006) concluded that in post nationalization period witnessed an unprecedented expansion of banking industry in India. However accompanied inefficiency and poor financial health to over come this problem and improve he efficiency of banks, various tectonic measures were taken since 1991. This has resulted in improvement in productivity, profitability and strengthening of financial position of the banks so much that they are outshining those of advanced notions. However banks have still o go a long way to sustain their Competitive success. Indian Commercial Banks also need to enhance their system and procedure to international standards and also simultaneously fortify their financial position. Subbaroo (2007) concludes the Indian banking system has undergone transformation itself from domestic banking to international banking. However, the system requires a combination of new technologies, well regulated risk and credit appraisal, treasury management, product diversification, internal control, external regulations and professional as well as skilled human resource to achieve the heights of the international excellence to play its role critically in meeting the global challenge. This paper mainly concentrates on the major trends that change the banking industry world over, viz. consolidation of players through mergers and acquisitions globalization of players, development of new technology, universal banking and human resource in banking, profitability, rural banking and risk management. Banks will have to gear up to meet stringent prudential capital adequacy norms under Basel I and II, the free trade agreements. Banks will also have to cope with challenges posed by technological innovations in banking.

Tiwari, Bure, and Harstatte (2006) explores the various avenues using the mobile technology for expanding online banking services, as mobile based applications gain popularity. The paper presents the global scenario and technology used in mobile financial services. The paper provides a global overview over services offered and simultaneously analysis various MFS technologies. Using case study it shows how successful offers may be conceptualized and implemented in a real world setting. Uppal (2008) analyzed that the quality of ebanking services in the changing environment. The paper concludes that the customers of e-banks are satisfied with the different e-channels and their services in the spread of e-banking services. This paper also suggests some measures to make e-banking service more effective in the future. The present study is mainly concerned with the Indian banking industry in general and particular those banks that are producing service 
through e-channels i.e. e-banks. The sample size of bank customers is 25. The data is collected through pretested and well structured questionnaire in Ludhiana, Punjab in May, 2006.

Uppal and Kaur (2007) analysis the efficiency of all the bank groups in the post banking sector reforms era. Time period of study is related to second post banking sector reforms (1999-2000 to 2004-05). The paper concludes that the efficiency of all the bank groups has increased in the second post banking sector reforms period but these banking sector reforms are more beneficial for new private sector banks and foreign banks. This paper also suggests some measures for the improvement of efficiency of Indian nationalized banks. The sample of the study in Indian banking industry which comprises five different ownership groups and the ratio method is used to calculate the efficiency of different bank groups. New private sector banks are compelling with foreign banks for continuous improvement in their performance.

\section{Results and Discussion}

Profitability per Employee: The profit per employee is in the range of Rs.0.41 to 2.32 lakhs during the study period in G-I, similarly, it was between Rs.0.77 to 2.04 lakhs in G-II, Rs.1.08 to 6.15 lakhs in G-III and Rs.8.07 to 15.17 lakhs in G-V. The G-I, II (Public Sector Banks), even old private sector banks (G-III) have shown poor efficiency in terms of profit per employee as compared to new private sector banks and foreign banks. But our new private sector banks are competing with the foreign banks whose average performance is higher (18.14) as compared to foreign banks where average is only 11.68 in at the end of the study period.

This overall trend of increasing employee profitability may be attributed to the reduction in the number of employees following the launch of VRS by some of the Indian banks as well as higher profits by the banks. On an average, new private sector banks enjoy a higher increase in their profitability per employee, as compared with their counter part public sector banks. This may be attributed largely to the better technology that the new private sector banks employ, besides the advantage of carrying no historical baggage.

ICICI and HDFC Banks in G-IV are dominating in profit per employee whereas Corporation Bank, OBC and PNB have the higher per employee profit in G-I whereas Punjab \& Sindh Bank, UCO Bank and Dena Bank are responsible for lowering the profit per employee.

Profitability per Branch: For Indian public sector banks, the profits per branch were in the range of Rs.6.39 to $41.08 \mathrm{cr}$. during the study period. Among the Indian banks, new private sector banks displayed the highest profits per branch that lie between Rs.19.09 to $174.34 \mathrm{cr}$. But overall, foreign banks show excellent results in this parameter. The profitability per branch was in the range of Rs.623.56 to $1405.67 \mathrm{cr}$. On an inter-temporal basis, per branch profits have been increasing gradually in the Indian banking sector. The growth in branch profits for Indian banks is attributable to the overall increase in profitability in the banking industry. In the case of the foreign peer group, profitability per branch shows a small increase over the period covered by this study. Hence, on an average, branch profitability of foreign banks is higher than that of G-I, II, III \& IV. But, we can also say that G-IV is quite active and competing with foreign banks.

Expenses per Employee: On an average, Indian bank pays less as compared to foreign banks. Among Indian banks, new private sector banks pay on an average Rs.59.83 lakhs as compared to G-I, II \& III who pay Rs.14.00, 14.43 \& 18.07 lakhs respectively. The highest expenses per employee incurred by G-V (foreign banks) having Rs.79.84 lakhs per employee. The G-IV \& G-V pays higher and attractive salary to the efficient employees; they also provide better facilities and incentives to their employees. Due to this reason, per employee expenses are higher even return per employee is much higher as compared to their counterparts.

Expenses per Branch: Among the Indian banks, average per branch expenses incurred by new private sector banks (G-IV) is at the tune of Rs.1169.06 lakhs as compared to G-I, II \% III with branch expenses of Rs.205.34, 303.38 \& 228.74 lakhs respectively. But branch expenses are the highest in G-V having amount of Rs.6364.72 lakhs for each branch. Overall, we may conclude that among the Indian bank groups, new private sector banks had shown excellent growth in their efficiency and this group is competing with foreign banks in terms of many parameters of efficiency. Number of factors are contributing in their excellent efficiency performance like work culture, dedication, loyalty, technology, better facilities, new products/services, management, transparency etc. 
Business per Employee: Since different employees in a bank contribute in different ways to the revenues and profits of a bank, it is difficult to come up with one universal metric that captures the business per employee accurately. The business per employee is quite low in G-I, II \& III as compared to G-IV \& V. the average per employee business is the highest in G-IV i.e. Rs.905.83 lakhs and G-V has an average of Rs.901.50 lakhs during the study period. Thus, deposits mobilization and advances per employee are higher in G-IV \& V. These bank groups are providing a better interest on deposits and lower interest on advances; their market policies are quite effective as compared to Indian public sector banks.

III as compared to that of G-IV \& V. it was only Rs.2704.17 lakhs in G-I whereas it was Rs.17659.17 lakhs in GIV and Rs.73263.17 lakhs in G-V. In this parameter, foreign banks have lion's share among all the Indian bank groups. Hence, the new private sector banks in India have led the way in this regard, because of the better use of technology and other infrastructure.

\section{Challenges and Future Opportunities for Indian Banking Sector}

The efficiency of public sector banks is quite low, when we compare with that of foreign banks. The public sector banks are facing many challenges but at the same time there are many opportunities, the question is only of the mindset.

High level of NPAs: one of the challenges faced by the banking sector today is the high level of NPAs. To tackle with this critical problem, different options are available which includes:

- $\quad$ Reducing the existing NPAs and curbing their further build-up.

- Exploring avenues of recovering NPAs such as Lok Adalats for recovering smaller loans.

- Increasing the number of Debt Recovery Tribunals.

- Complete ban on generalized loan waivers.

- Setting up the Asset Reconstruction Fund (ARF) as recommended by the NC (1991) and reiterated in its second report (1998).

- $\quad$ Reduce the recovery rate.

Loss making branches and overstaffing: Another challenge is the very large number of loss making branches overstaffed and the archaic methods of operations. All these factors have affected the efficiency of public sector banks negatively. To cope up with this problem, public sector banks should close up loss making branches and staff should be according to the requirements.

Culture of blackmailing in public sector banks: This is also another major area, which prevails in most of the public sector banks and adversely affects the efficiency of the employees. The Central Vigilance Commission (CVC) has said no action to be taken on anonymous/pseudonymous petition is a measure, which would give confidence to the honest people in the banking sector. CVC should ensure that the honest officers do not become victims of blackmail.

Frauds committed by insiders: Many a times, the insiders commit the frauds. CVC recommend high punishment should be given to win the customers back and to create the more faith.

Technology: The public sector banks are not using technology aggressively. Only 80 pc of the business of all public sector banks have been computerized whereas new private sector banks and foreign banks have 100 pc of their business computerized and they are providing e-banking services. Public sector banks should now aim for computerization not only branch wise but bank wide too. Bank wide computerization with the capacity to focus on the customers and develop a culture of customer focus services mindset is perhaps needed in today's for facing the future.

Innovative methods: The foreign banks and new private sector banks are using innovative marketing methods but our public sector banks are lacking. In the emerging environment, two aspects have become important. One is the better corporate governance and the second is innovativeness and development of competitive edge through imagination. So for as better corporate governance is concerned, what is needed is 
ensuring that there is transparency in the system of decision making and that lead to accountability which again lead to shareholders and stakeholders.

Poor Asset Quality of public sector banks: Public sector banks should concentrate on asset quality and earnings

Autonomy in HRM: Autonomy in HRM related decisions such as deciding categorization of branches, vacancy, placements should be given to banks.

WTO \& Public Sector Banks: Public sector banks must look into wider issues and reap the overall economic benefits of free trading environment. There is dearth of adequate awareness in the banking industry about the implications of the agreement and several issues related to WTO.

More attention towards customer expectations: With the increasing competition among banks, to meet customer expectations, banks should offer a broader range of deposits, investments and credit products through diverse distribution channels including upgraded branches, ATMs, telephone, Internet. For this purpose, banks should:

- Become more customers centric, offering a wide range of products/services through multiple delivery channels.

- Become proficient in managing assets and liabilities according to risk and returns.

- Pay greater attention to efficiency including cost-reduction and increasingly fee-based income

In brief, public sector banks should follow these measures to make themselves up to date:

- Create a clear, simple, reality based customer-focused vision and are able to communicate its strategies forwardly to all branches.

- Reach, set aggressive targets, recognize and reward progress, while understanding accountability and commitment.

- Have a passion for excellence; hate bureaucracy and all the nonsense that comes with it.

- Have the self-confidence to empower others and behave in a boundary less fashion.

- Have, or have the capacity to develop global brains and global sensitivity and are comfortable building diverse and global teams.

- Have enormous energy and the ability to energize and invigorate others, stimulate and relish change and not be frightened or paralyzed by it; see change as an opportunity not a threat.

- Possess a mindset that drives quality, cost and speed for a competitive advantage.

To make public sector banks a world-class, five factors are important to consider and create:

- Vision

- Values

- Innovations

- Leadership

- Social Commitment

\section{Conclusion}

The main implication of this study is that public sector banks although has improved their financial position but still these banks need many changes. To make them a world-class in the era of competitive environment, five factors are important to consider, vision, values, innovations, leadership and social commitment these can convert the challenges of public sector banks into opportunities. On the basis of some important parameters of efficiency, paper concludes that among the Indian banks, efficiency of new private sector banks is quite high, but foreign banks have even edge over new private sector banks. Our new private sector banks are competing with foreign banks with continuous improvement in their performance. But our public sector banks should make effective, innovative policies/strategies to compete with foreign banks if they want to survive in this emerging competitive environment. The vision, values, innovations, leadership and social commitment can convert the challenges of public sector banks into opportunities. 


\section{Future Areas of Comprehensive Research}

In the era of LPG and WTO, a comprehensive research is needed regarding:

- WTO and how to create opportunities for Indian banks.

- A comprehensive study regarding non-interest income.

- Policies and strategies.

- Ways and mans for the globalization of Indian banks.

- Recent partial privatization of Indian public sector banks and their performance

\section{References}

Harold, L. (2006). Performance Measurement and Management of Technology in Indian Banking: New Approaches. Contributors, I, Banknet India, 5: 6-18.

Mariappan, V. (2005-06). Changing the Way of Banking in India. Vinimaya, 26(2): 26-34.

Patnaik, S. (2004). Shared ATMs- The Way Forward. IBA Bulletin, 26(12): 24-27.

Srivastava, R. M. (2006). Indian Commercial Banks on Path towards Competitive Efficiency. Vinimaya, 27(3): 5-12.

Subbaroo, P. S. (2007). Changing Paradigm in Indian Banking. Gyan Management, 4(2): 151-160.

Singla, H. K. (2008). Financial Performance of Banks in India. The ICFAI Journal of Bank Management, 22(1): 50-62.

Tiwari, R., Bure, S. and Harstatte, C. (2006). Mobile-Banking: The Concept, Opportunities and Challenges. Contributors, II, Banknet India, 9: 59-71.

Uppal, R. K. (2008). Customer Perception of E-Banking Services of Indian Banks: Some Survey Evidence. The ICFAI Journal of Bank Management, 7(1): 63-74.

Uppal, R. K. and Kaur, R. (2007). Indian Banking Sector: Efficiency in the Post- Banking Sector Reforms EraNew Challenge and Future Opportunities. Prestige Journal of Bank Management and Research, 2(1): 42-55. 